\section{FRI0445 IDENTIFICATION OF PSORIATIC ARTHRITIS USING AN ADMINISTRATIVE CLAIMS-BASED ALGORITHM}

Hemin Lee ${ }^{1}$, Julia Ford ${ }^{2}$, Yinzhu Jin ${ }^{1}$, J Adrian. Santiago Ortiz ${ }^{1}$, Angela Y. Tong ${ }^{1}$, Seoyoung Kim ${ }^{1,2}$. ${ }^{1}$ Brigham and Women's Hospital, Division of

Pharmacoepidemiology and Pharmacoeconomics, Department of Medicine, Boston, United States of America; ${ }^{2}$ Brigham and Women's Hospital, Division of Rheumatology, Immunology, and Allergy, Boston, United States of America

Background: Accurately identifying psoriatic arthritis (PsA) in large electronic healthcare database is critical for epidemiological studies.

Objectives: To develop and validate a claims-based algorithm to identify patients with PsA.

Methods: We conducted a retrospective chart review of the Partners Healthcare electronic medical record linked to Medicare claims from year 2012 to 2014. 7 claims-based algorithms were developed to identify PsA: 1) $\geq 2$ International Classification of Diseases, Ninth Revision (ICD-9) codes for PsA (696.0) and at least one diagnosis of psoriasis (696.1) by any physician; 2) $\geq 2$ diagnosis of PsA with at least 1 diagnosis by rheumatologist; 3) $\geq 2$ PsA diagnosis with at least 1 diagnosis by rheumatologist and $\leq 1$ diagnosis of rheumatoid arthritis $(714.0) ; 4) \geq 2$ diagnosis of PsA and at least 1 diagnosis of psoriasis by dermatologist; 5$) \geq 1$ diagnosis of PsA by rheumatologist and $\geq 1$ diagnosis of psoriasis by dermatologist; 6 ) $\geq 2$ diagnosis of PsA by any physician and $\geq 1$ claims for PsA medication; 7) $\geq 2$ diagnosis of PsA with at least 1 diagnosis by rheumatologist and $\geq 1$ claims for PSA medication. The ICD-9 codes were separated by $\geq 7$ days but $<365$ days. Medical record by the treating physician was considered as the gold standard, and two independent physicians confirmed the presence of PsA. Positive predictive value (PPV) and 95\% confidence intervals $(\mathrm{Cl})$ of the algorithms were calculated.

Results: The 7 algorithms identified 357, 399, 315, 223, 215, 372, and 276 records, respectively. Approximately $45 \%$ of the identified records with adequate data were reviewed. The PPV of the algorithms ranged from $75.2 \%$ to $88.6 \%$ (Table 1). Mean age of identified PsA patients ranged from 72.6 to 73.5 years old. Presence of psoriasis 1 year prior to index date of PsA ranged from $54.2 \%$ to $89.2 \%$. Algorithm 6 which captured $\geq 2$ diagnosis of PsA and $\geq 1$ claims for PsA-related medications identified second highest number of patients $(n=372)$ yet still yielded high PPV of $82.4 \%(95 \% \mathrm{Cl} 76.5,88.3)$.

Conclusion: All seven claims-based algorithms had a high PPV of 75$89 \%$ in identifying PsA. A claims-based algorithm utilizing two or more diagnosis codes of PsA by any physician with a claim for PsA medication can be a useful and efficient tool to identify the PsA population in large claims databases.

\section{REFERENCES :}

[1] Ciccia F, et al. The New England journal of medicine. May 25 2017;376 (21):2094-2095

Table 1. Predictive Values of Proposed Algorithms for Identifying Psoriatic Arthritis

\begin{tabular}{|c|c|c|c|}
\hline Algorithms & $\begin{array}{l}\text { Records } \\
\text { Identified }\end{array}$ & $\begin{array}{c}\text { Charts } \\
\text { Reviewed } \\
\text { (\%) }\end{array}$ & $\begin{array}{c}\text { PsA per } \\
\text { treating MD, } \\
\text { PPV\% } \\
(95 \% \mathrm{Cl})\end{array}$ \\
\hline \multicolumn{4}{|l|}{ Diagnosis only } \\
\hline $\begin{array}{l}\text { 1. } \geq 2 \text { diagnosis of PsA and } \geq 1 \text { diagnosis of } \\
\text { psoriasis by any physician }\end{array}$ & 357 & $\begin{array}{c}141 \\
(39.5)\end{array}$ & $\begin{array}{c}75.2 \\
(68.0,82.3)\end{array}$ \\
\hline \multicolumn{4}{|l|}{ Diagnosis with Specialist Visit } \\
\hline $\begin{array}{l}\text { 2. } \geq 2 \text { diagnosis of PSA with at least } 1 \text { diagnosis } \\
\text { by rheumatologist }\end{array}$ & 399 & $\begin{array}{c}185 \\
(46.4)\end{array}$ & $\begin{array}{c}80 \\
(74.2,85.8)\end{array}$ \\
\hline $\begin{array}{l}\text { 3. } \geq 2 \text { diagnosis of PSA with at least } 1 \text { diagnosis } \\
\text { by rheumatologist and } \leq 1 \text { diagnosis of RA }\end{array}$ & 315 & $\begin{array}{c}147 \\
(46.7)\end{array}$ & $\begin{array}{c}81.6 \\
(75.4,87.9)\end{array}$ \\
\hline $\begin{array}{l}\text { 4. } \geq 2 \text { diagnosis of PsA and at least } 1 \text { diagnosis } \\
\text { of psoriasis by dermatologist }\end{array}$ & 223 & $\begin{array}{c}95 \\
(42.6)\end{array}$ & $\begin{array}{c}77.9 \\
(69.6,86.2)\end{array}$ \\
\hline $\begin{array}{l}\text { 5. } \geq 1 \text { diagnosis of PsA by rheumatologist and } \\
\geq 1 \text { diagnosis of psoriasis by dermatologist }\end{array}$ & 215 & $\begin{array}{c}114 \\
(53.0)\end{array}$ & $\begin{array}{c}85.1 \\
(78.5,91.6)\end{array}$ \\
\hline \multicolumn{4}{|l|}{ Diagnosis and Medication Dispensing } \\
\hline $\begin{array}{l}\text { 6. } \geq 2 \text { diagnosis of } P s A \text { and at least } 1 \\
\text { medication dispensing for PsA }\end{array}$ & 372 & $\begin{array}{c}159 \\
(42.7)\end{array}$ & $\begin{array}{c}82.4 \\
(76.5,88.3)\end{array}$ \\
\hline $\begin{array}{l}\text { 7. } \geq 2 \text { diagnosis of PsA with at least } 1 \text { diagnosis } \\
\text { by rheumatologist and at least } 1 \text { medication }\end{array}$ & 276 & $\begin{array}{c}123 \\
(44.6)\end{array}$ & $\begin{array}{c}88.6 \\
(83.0,94.2)\end{array}$ \\
\hline
\end{tabular}

PsA, Psoriatic arthritis; MD, Medical doctor; PPV, Positive predictive value; ICD,

International Criteria of Diagnosis; RA, Rheumatoid arthritis

Acknowledgement: This study was supported by an investigator-initiated research grant from Pfizer.
Disclosure of Interests: Hemin Lee: None declared, Julia Ford: None declared, Yinzhu Jin: None declared, Adrian J. Santiago Ortiz: None declared, Angela Y. Tong: None declared, Seoyoung Kim Grant/research support from: Pfizer, Bristol-Myers Squibb, Roche/Genentech and AbbVie. DOI: 10.1136/annrheumdis-2019-eular.332

\section{FRI0446 ATTAINMENT OF MINIMAL DISEASE ACTIVITY (MDA) IN PSORIATIC ARTHRITIS (PSA) PATIENTS (PTS) DEPENDING ON THE TIME OF SYNTHETIC (S) DMARDS INITIATION IN CLINICAL PRACTICE: RUSSIAN PSA REGISTRY (RU-PSART) DATA}

Elena Loginova ${ }^{1}$, Tatiana Korotaeva ${ }^{1}$, Anastasia Koltakova ${ }^{1}$, Elena Gubar ${ }^{1}$, Yulia Korsakova ${ }^{1}$, Maria Sedunova ${ }^{2}$, Igor Pristavsky ${ }^{2}$, Irina Umnova ${ }^{3}$, Irina Bondareva ${ }^{4}$, Snezana Kudishina ${ }^{5}$, Alexander Lila ${ }^{1} .{ }^{1}$ Nasonova Research Institute of Rheumatology, Moscow, Russian Federation; ${ }^{2}$ St. Petersburg Clinical Rheumatology Hospital No.25, St. Petersburg, Russian Federation; ${ }^{3}$ Omsk Regional Hospital, Omsk, Russian Federation; ${ }^{4}$ Kemerovo Regional Hospital, Kemerovo, Russian Federation; ${ }^{5}$ Vladivostok Clinical Hospital No.2, Vladivostok, Russian Federation

Background: According to the EULAR recommendations and treat to target strategy SDMARD are the first line of PsA therapy. The goal of PsA treatment is attaining MDA. But there are contradictory data about the efficacy of sDMARDs in PsA pts. Data was collected from 25 rheumatology clinics of the Russian Federation.

Objectives: To investigate the cumulative frequency and the time of MDA attainment in early and long-term PsA after starting sDMARDs in clinical practice.

Methods: 253 (M/F-93/160) PsA pts according to CASPAR criteria were included in the RU-PsART, after signing consent participation forms; median (Me) age 47 [Min 20 - Max 82] years (yrs.). All patients were divided into two groups according to disease duration at time of sDMARDs initiation: early $\mathrm{PsA} \leq 2$ yrs. (165pts) and long-term $\mathrm{PsA}>2$ yrs (88pts). All pts underwent standard clinical examinations of PsA and psoriasis activity. All pts were treated with the following sDMARDs: Oral Methotrexate (MTX) (103pts), intramuscular MTX (30pts), subcutaneous MTX (78pts), Leflunomide (7pts), Sulfasalazine (24pts), Apremilast (10pts), Tofacitinib (1pts). MDA was defined as $>5$ of the following criteria: tender joint count $\leq 1$, swollen joint count $\leq 1$, PASI $\leq 1$ or $B S A \leq 3$, patient pain global assessment $V A S \leq 15$, patient's global disease activity VAS $\leq 20, H A Q \leq 0,5$, enthesitis count $\leq 1$. The cumulative frequency and the time of MDA attainment were calculated in both groups. Kaplan-Meier cumulative analysis, Me [Min-Max], ORs with 95\% Cl,\%, Breslow, Tarone-Ware, Log Rank tests were performed. All $\mathrm{Cl}>1, \mathrm{p}<0.05$, were considered to indicate statistical significance.

Results: MDA has been achieved by the use of sDMARDs treatment in 39 out of 165 (24\%) pts with early PsA and in 4 out of 88 (5\%) pts with long-term PsA. Early PsA pts have more chance to achieve MDA in comparison to long-term PsA pts, OR=6.5 [Cl 95\% 2.2-18.9]. Comparative analysis has shown that cumulative frequency of MDA achievement after sDMARDs initiation was significantly higher (42\% vs $5 \%)$ and faster $(21$ months vs 11 yrs.) in early PsA than in long-term PsA ( $p<0.05$ for Breslow, Tarone-Ware and Log Rank tests) (Fig. 1). Fig. 1. Cumulative frequency and the time of MDA achievement after starting sDMARDs in early and long-term PsA.

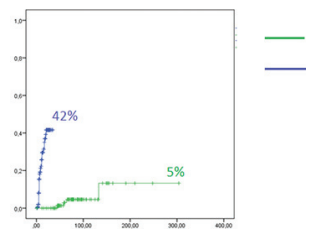

Conclusion: Our study suggests that sDMARDs initiation (mostly MTXmonotherapy) at an early stage of PsA allows to achieve MDA significantly faster and more often than in long-term PsA

Disclosure of Interests: Elena Loginova Speakers bureau: Novartis, Celgene Corporation, Biocad, Janssen, AbbVie Inc, Tatiana Korotaeva Speakers bureau: Novartis, Celgene Corporation, AbbVie Inc, Biocad, Janssen, Pfizer, UCB, Lilly, Anastasia Koltakova: None declared, ELENA GUBAR: None declared, Yulia Korsakova Speakers bureau: Celgene Corporation, Janssen, Maria Sedunova: None declared, Igor Pristavsky: None declared, Irina Umnova: None declared, Irina Bondareva: None declared, Snezana Kudishina: None declared, Alexander Lila Speakers bureau: Pfizer, Inc., MSD, Novartis, AbbVie Inc., Celgen Corporation, Biocad, Janssen, UCB, Inc. DOI: 10.1136/annrheumdis-2019-eular 1565 